\title{
Liver uptake of gold nanoparticles after intraperitoneal administration in vivo: A fluorescence study
}

\author{
Mohamed Anwar K Abdelhalim ${ }^{1 *}$ and Mohsen Mahmoud Mady ${ }^{1,2}$
}

\begin{abstract}
Background: One particularly exciting field of research involves the use of gold nanoparticles (GNPs) in the detection and treatment of cancer cells in the liver. The detection and treatment of cancer is an area in which the light absorption and emission characteristics of GNPs have become useful. Currently, there are no data available regarding the fluorescence spectra or in vivo accumulation of nanoparticles (NPs) in rat liver after repeated administration. In an attempt to characterise the potential toxicity or hazards of GNPs in therapeutic or diagnostic use, the present study measured fluorescence spectra, bioaccumulation and toxic effects of GNPs at 3 and 7 days following intraperitoneal administration of a $50 \mu \mathrm{l} /$ day dose of 10, 20 or $50 \mathrm{~nm}$ GNPs in rats.
\end{abstract}

Methods: The experimental rats were divided into one normal group $(\mathrm{Ng})$ and six experimental groups (G1A, G1B, G2A, G2B, G3A and G3B; G1: 20 nm; G2: 10 nm; G3: 50 nm; A: infusion of GNPs for 3 days; B: infusion of GNPs for 7 days). A $50 \mu \mathrm{l}$ dose of GNPs (0.1\% Au by volume) was administered to the animals via intraperitoneal injection, and fluorescence measurements were used to identify the toxicity and tissue distribution of GNPs in vivo. Seventy healthy male Wistar-Kyoto rats were exposed to GNPs, and tissue distribution and toxicity were evaluated after 3 or 7 days of repeated exposure.

Results: After administration of 10 and $20 \mathrm{~nm}$ GNPs into the experimental rats, two fluorescence peaks were observed at $438 \mathrm{~nm}$ and $487 \mathrm{~nm}$ in the digested liver tissue. The fluorescence intensity for 10 and $20 \mathrm{~nm}$ GNPs (both first and second peaks) increased with the infusion time of GNPs in test rats compared to normal rats. The position of the first peak was similar for G1A, G2A, G1B, G2B, G3B and the normal (438 nm); that for G3A was shifted to a longer wavelength $(444 \mathrm{~nm})$ compared to the normal. The position of the second peak was similar for G1A, G1B, G2A, G2B and the control $(487 \mathrm{~nm})$, while it was shifted to a shorter wavelength for G3A (483 nm) and G3B (483 nm). The fluorescence intensity of the first and second peaks increased for G1A, G2A, G1B and G2B, while it decreased for G3A and G3B compared to the control.

Conclusions: The fluorescence intensity of GNPs varied with the number, size and shape of particles and with the ratio of surface area to volume in a given sample. Fluorescence intensity changes during infusion depended on the size and shape of GNPs, with smaller particles experiencing larger changes during the infusion time in addition to the quenching produced by the larger GNPs. It is likely that smaller particles, which have a much higher ratio of surface area to volume compared to larger particles, are more prone to aggregation and surface interaction with biological components. This study suggests that fluorescence intensity can be used to evaluate bioaccumulation and the toxicity of gold nanoparticles in rats.

Keywords: gold nanoparticles, sizes, time-dependent effects, liver tissue, fluorescence spectroscopy

\footnotetext{
* Correspondence: abdelhalimmak@yahoo.com

'Department of Physics and Astronomy, College of Science, King Saud

University, P.O. 2455, Riyadth 11451, Saudi Arabia

Full list of author information is available at the end of the article
} 


\section{Introduction}

Nanoparticles (NPs) offer great promise for biomedical applications, particularly in pharmaceutical delivery and novel diagnostic and therapeutic methods [1].

Despite the many potential therapeutic benefits of nanoparticles, some studies indicate that certain nanoparticles, due to their small size and unique physical properties, may cause adverse effects [2,3]. The size, surface area and dosage of particles all appear to play important roles in mediating nanoparticle toxicity. It has been proposed, for example, that the size of nanoparticles influences their adhesion to and interaction with living cells [4].

The small size of NPs may enable interactions with specific biological targets. Furthermore, metallic NPs can be made to exhibit a resonant response to a time-dependent magnetic field, producing a potentially useful energy transfer to the particles $[5,6]$. Therefore, such particles have been used as hyperthermic agents that deliver lethal amounts of thermal energy to targets such as tumours [7-9].

Gold NPs (GNPs) show several features that make them well suited for biomedical applications, including straightforward synthesis, stability, and the potential for surface modification with active biological molecules such as peptides or proteins [5].

Semmler-Behnke et al. observed that a considerable percentage of $18 \mathrm{~nm}$ GNPs is removed from the blood and trapped predominantly in the liver and spleen [10].

Fluorescence is the emission of light by a substance following absorption of light or other electromagnetic radiation of a different wavelength. In most cases, the emitted light has a longer wavelength, and therefore lower energy, than the absorbed radiation. However, when the absorbed electromagnetic radiation is intense, it is possible for one molecule to absorb two photons; this two-photon absorption can lead to emission of radiation having a shorter wavelength than the absorbed radiation.

The origin of the unique optical properties of GNPs is a phenomenon known as surface plasmon resonance (SPR). The exposure of nanoparticles to electromagnetic radiation of a wavelength much smaller than the GNP diameter induces coherent, resonant oscillations of the conductionband electrons across the nanoparticles. These oscillations are known as the SPR, which lies in the visible frequency range and results in strong optical absorbance and scattering by the GNPs $[11,12]$. This phenomenon has been exploited in many applications of GNPs, such as Raman sensors [13], photocatalysts [14], and photoelectrochemical materials $[15,16]$. In the bioscience and medical fields, GNPs are used as immunostaining labels for electron microscopy and as chromophores for immunoreactions and nucleic acid hybridisation $[17,18]$.

Despite these many useful applications of NPs, numerous studies have shown that exposure to smaller-sized particles produces greater inflammatory and cytotoxic responses compared to exposures to larger-sized particles at the same mass concentration [19]. It is believed that smaller-sized particles are more reactive with biological components and produce adverse effects due to the large surface area and large number of particles in a nanoparticle preparation compared to a larger-particle preparation [20].

The toxicity of NPs is thought to depend on the size, surface area, composition, and shape of the nanomaterial. Particle size plays a role in how the body responds to, distributes, and eliminates materials [14,15]; it can also affect the mode of endocytosis and cellular uptake and the efficiency of particle processing in the endocytic pathway $[21,22]$. Therefore, for applications of GNPs in therapy and drug delivery, it is necessary to know the bioaccumulation and local or systemic toxicity associated with the nanoparticles.

The particle-size-dependent organ distribution of GNPs has been studied in vivo [23-26]. Hyllier and Albertch showed that orally administered GNPs appeared in various tissues in mice, and that smaller particles were more readily absorbed and more widely distributed in the body than were larger particles [23]. In most studies, systemically administered NPs were primarily taken up by the liver and spleen, with lesser quantities taken up by the lung, kidney, heart, and brain after a single administration. However, little is known about the biodistribution, accumulation and toxicity of GNPs after repeated administration.

GNPs can be used in various biomedical applications; however, very little is known about the size, dose and exposure dependence of in vivo nanoparticle processing kinetics. Furthermore, there are currently no data available regarding the fluorescence spectra and accumulation of nanoparticles (NPs) in rat liver following repeated in vivo administration.

\section{Materials and methods \\ Gold nanoparticles (GNPs)}

GNPs of different sizes $(10,20$ and $50 \mathrm{~nm}$; products MKN-Au-010, MKN-Au-020 and MKN-Au-050, Canada, respectively) were purchased. All GNPs used in this study were in aqueous solution at a concentration of $0.01 \%$. The mean size and morphology of these GNPs were evaluated from transmission electron microscope (TEM) images. The high electron density of gold makes this method particularly suitable for evaluating the homogeneity of the nanoparticles in terms of shape and size.

\section{Animals}

Healthy male Wistar-Kyoto rats were obtained from the Laboratory Animal Centre (College of Pharmacy, King Saud University). Rats of age 8-12 weeks (approximately 250 g body weight) were housed in pairs in humidity- and 
temperature-controlled ventilated cages on a $12 \mathrm{~h}$ day/ night cycle. A conventional rodent diet and water were provided. Forty rats were individually caged and divided into a control group (NG: $\mathrm{n}=10$ ), group 1 (A: infusion of $20 \mathrm{~nm}$ GNPs for 3 days; $\mathrm{n}=5$; B: infusion of $20 \mathrm{~nm}$ GNPs for 7 days; $\mathrm{n}=5$ ), group 2 (A: infusion of $10 \mathrm{~nm}$ GNPs for 3 days; $\mathrm{n}=5$; B: infusion of $10 \mathrm{~nm}$ GNPs for 7 days; $\mathrm{n}=5$ ) and group 3 (A: infusion of $50 \mathrm{~nm}$ GNPs for 3 days; $\mathrm{n}=5$; $\mathrm{B}$ : infusion of $50 \mathrm{~nm}$ GNPs for 7 days; $\mathrm{n}=5$ ). In addition, histological investigations of 10 rats were performed in support of this study. Doses $(50 \mu \mathrm{l})$ of 10,20 or $50 \mathrm{~nm}$ GNPs in aqueous solution were administered to the animals via intraperitoneal injection every day for 3 or 7 days. The rats were anesthetised by inhalation of $5 \%$ isoflurane until muscular tonus relaxed. Blood and liver tissue were collected from each rat. A blood sample of approximately $1 \mathrm{ml}$ was obtained from each rat via venepuncture of an antecubital vein; the blood was mixed with $0.8 \mathrm{ml}$ of heparin to prevent coagulation. In order to assess tissue uptake, as much blood as possible was collected from the rats to maximise residual blood drainage from the organs. All experiments were conducted in accordance with guidelines approved by the King Saud University Local Animal Care and Use Committee.

\section{Digestion of liver tissue samples}

Liver tissue samples were wet-digested with nitric acid and stored as acidic digest solutions for analysis by fluorescence spectroscopy. The liver tissue was first freeze dried to minimise analyse loss and to facilitate subsequent sample preparation steps. The tissue was then homogenised to a fine powder by ball-milling in plastic containers. Approximately $0.20-0.25 \mathrm{~g}$ of powdered tissue was weighed into a Teflon reaction vessel and $3 \mathrm{ml}$ of $\mathrm{HNO}_{3}$ was added. The closed reaction vessel was heated in a $130^{\circ} \mathrm{C}$ oven until digestion was completed. Samples were then diluted to a final volume of $20 \mathrm{ml}$ with quartzdistilled water and stored in $1 \mathrm{oz}$. polyethylene bottles for subsequent fluorescence spectroscopy analysis.

\section{Fluorescence spectroscopy}

Fluorescence spectra of liver tissue containing GNPs of different sizes $(10,20$ or $50 \mathrm{~nm}$ ) were obtained using a FluoroMax-2 spectrofluorometer (JOBIAN YVON-SPEX, Instruments S. A., Inc., France). Fluorescence measurements were made over the wavelength range $250-700 \mathrm{~nm}$ using $1 \mathrm{~cm}$ path length quartz cuvettes, which were cleaned before each use by sonicating for $5 \mathrm{~min}$ in deionised water and then rinsing with deionised water.

\section{Results and discussion}

\section{Size and morphology of different GNPs}

The 10 and $20 \mathrm{~nm}$ GNPs showed spherical morphology with a narrow particle size distribution when dispersed in solution. The mean size for these GNPs was calculated from the TEM images. The mean measured size was $9.45 \pm 1.33 \mathrm{~nm}$ for $10 \mathrm{~nm}$ GNPs and $20.18 \pm 1.80 \mathrm{~nm}$ for $20 \mathrm{~nm}$ GNPs. GNPs of $50 \mathrm{~nm}$ diameters, in contrast, were not spherical but hexagonal in TEM images, as shown in Figure 1. The high electron density and homogeneous shape and size of the GNPs make them highly conspicuous under the TEM.

The maximum of the surface plasmon band (SPB) of GNPs in solution was shifted from $517 \mathrm{~nm}$ to $532 \mathrm{~nm}$ when the GNP size changed from $10 \mathrm{~nm}$ to $50 \mathrm{~nm}$. This effect was attributed to the surface plasmon oscillation of free electrons. After injecting $20 \mathrm{~nm}$ GNPs into the experimental rats, we observed two fluorescence peaks at $438 \mathrm{~nm}$ and $487 \mathrm{~nm}$ in the digested liver tissue.

Figures 2 and 3 show fluorescence spectra for 20 and 10 nm GNPs, respectively, following infusion periods of 3 and 7 days. The results show that the positions of the first and second peaks were nearly the same for G1A, G1B, G2A and G2B compared with the control while the fluorescence intensity for these peaks (both first and second) increased with increasing infusion period compared to the control.

Figure 4 shows fluorescence spectra for $50 \mathrm{~nm}$ GNPs following infusion periods of 3 and 7 days. The position of the first peak shifted to a longer wavelength (first peak: $444 \mathrm{~nm}$ ) and the second to a shorter wavelength (second peak: $483 \mathrm{~nm}$ ) for G3A compared to the normal. However, the position of the first peak was the same as control for $\mathrm{G} 3 \mathrm{~B}$, and the second peak shifted to a shorter wavelength $(483 \mathrm{~nm})$ compared to the normal. The fluorescence intensity of GNPs was lower for G3A (both first and second peaks) and much lower for G3B (both first and second peaks) compared to the control. This result may be attributed to any of three factors: 1) formation of a strong ground state complex between serum albumins and gold nanoparticles (static quenching); 2) differences in the physical and chemical properties of nanoparticles of different size and shape (as noted above, most $50 \mathrm{~nm}$ GNPs were hexagonal, and nanoparticle properties are highly size- and shape-dependent); or 3) faster uptake of and clearance by liver macrophages of the $50 \mathrm{~nm}$ GNPs compared to the other nanoparticles.

Figures 5 and 6 show fluorescence spectra for 10, 20 and $50 \mathrm{~nm}$ GNPs following infusion periods of 3 and 7 days, respectively.

Figure 5 shows the effect of particle size on GNP fluorescence spectra after an infusion period of 3 days (G1A, G2A and G3A). The first peak appears at a longer wavelength for G3A (444 $\mathrm{nm}$ ) compared to the other samples, in which the first peak is at nearly the same position as the normal. The second peak appears at nearly the same position for G1A, G2A and the normal, while that of G3A is shifted to shorter wavelength $(483 \mathrm{~nm})$. The 


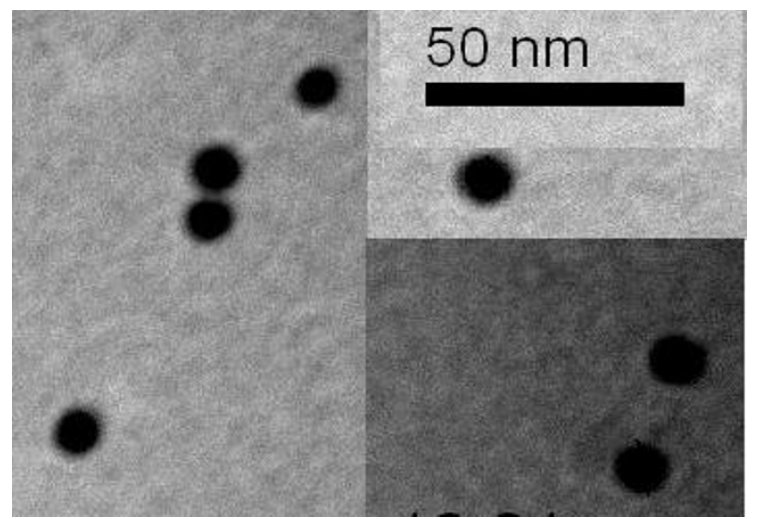

$10 \mathrm{~nm}$

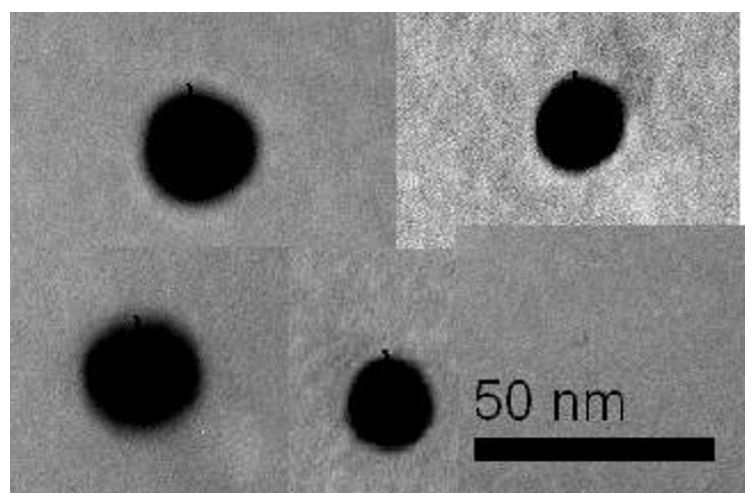

$20 \mathrm{~nm}$

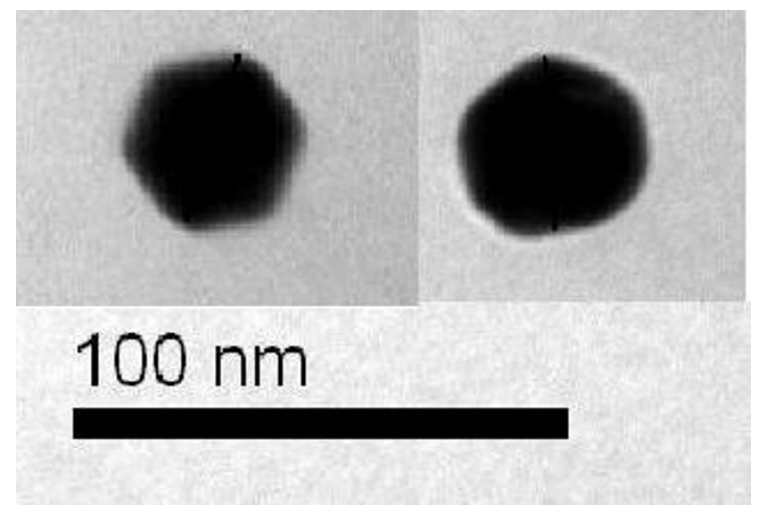

$50 \mathrm{~nm}$

Figure 1 TEM images for different GNP samples

intensity of the two peaks was higher for G1A and G2A compared to the normal, while that in the G3A spectrum was lower.
Figure 6 shows the results of the same experiment after an infusion period of 7 days. The position of the first peak is nearly the same for G1B, G2B, G3B and the normal, while the position of the second peak is nearly the same for G1B, G2B and the normal, while the G3B peak is shifted to a shorter wavelength $(483 \mathrm{~nm})$. The intensity of both peaks was higher for G1B and G2B than for the normal, while the intensity of these peaks in the G3B spectrum was lower.

Figure 7 shows the effect of size on the fluorescence spectra of GNPs after infusion periods of 3 days (G1A, G2A and G3A) and 7 days (G1B, G2B and G3B). The first peak is shifted to a longer wavelength for G3A (444 $\mathrm{nm}$ ) but is nearly the same for all other samples compared to the normal. The second peak is at nearly the same position for G1A, G1B, G2A, G2B and the normal, while it is shifted to a shorter wavelength for G3A and G3B. The intensity of both peaks is higher for G1A, G2A, G1B and G2B and lower for G3A and G3B compared to the normal.

Nanotechnology has recently emerged as a promising field for the treatment and diagnosis of a variety of diseases [1]. GNPs are particularly promising because of their ease of synthesis in various shapes and the potential for conjugation with peptides and proteins, which can target the GNPs to specific interaction partners [6].

The results of this study indicate that decreasing nanoparticle size, which produces an exponential increase in surface area relative to volume, may make the GNPs more self-reactive (i.e., may promote aggregation) and more prone to interactions with surrounding molecules (biological components). Moreover, increased uptake of nanoparticles may lead to accumulation in certain tissues, where the particles may interfere with critical biological functions $[16,21]$. We note that the rate of exocytosis of GNPs is size dependent; larger GNPs are more readily accumulated in the cell [27].

To evaluate the time dependence of GNP distribution and aggregation, we administered $50 \mu \mathrm{l}$ of GNPs of (10, 20 and $50 \mathrm{~nm}$ ) by daily intraperitoneal injection into rats for periods of 3 or 7 days. At these time points, the bio-distribution of the GNPs was quantitatively measured by fluorescence spectroscopy and TEM. The size of the GNPs strongly influenced the bio-distribution.

The very small size of nanoparticles imparts physical and chemical properties that are very different from those of the same material in bulk form. Nanoparticles have a larger surface area to volume ratio compared to bulk materials; they may thus exhibit an enhanced or hindered tendency to aggregate (depending on the surface chemistry), enhanced photoemission, high electrical or heat conductivity, or improved surface catalytic activity $[19,21]$. 


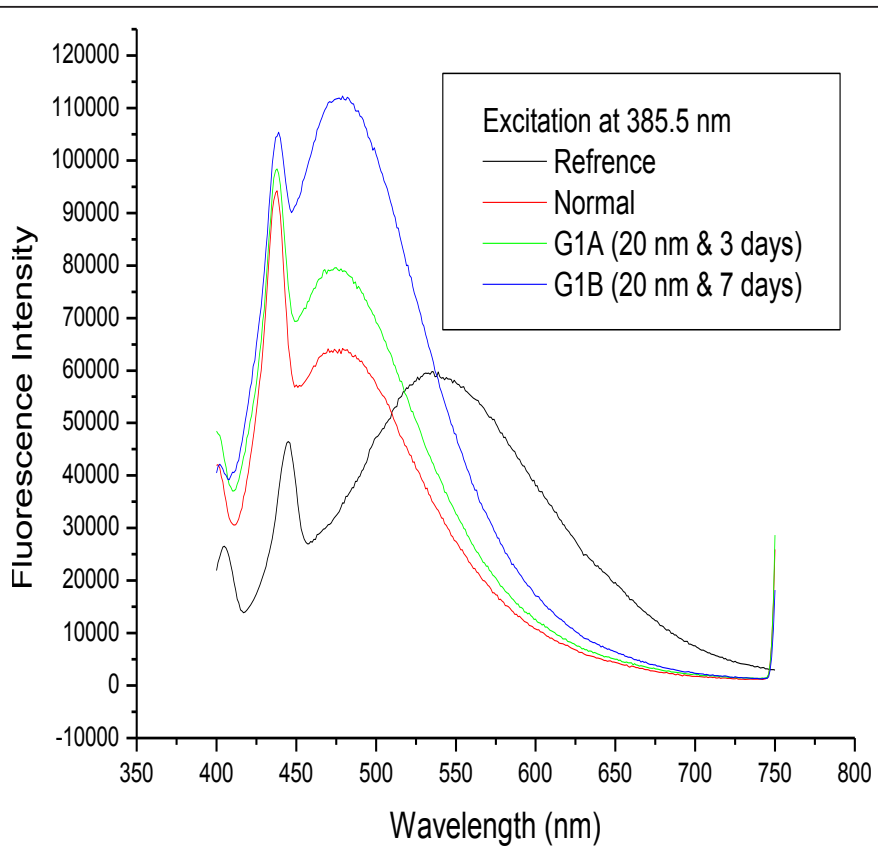

Figure 2 The fluorescence emission peak intensity after infusion periods of 3 and 7 days for $20 \mathrm{~nm}$ GNPs.

Because nanoparticle surfaces can interact with biological components, nanoparticles may be more reactive than larger particles toward biomolecules. It has been shown, for example, that the severity and the likelihood of inflammatory response transiently increased, within $12 \mathrm{~h}$, following injection of 200 or $100 \mathrm{~nm}$ GNPs into experimental animals. GNPs were ultimately trapped by macrophages in the spleen and liver and remained in these tissues until 4 weeks after the single injection [17].

To evaluate the impact of particle size on tissue distribution, we injected rats with $50 \mu \mathrm{l}$ GNPs of different sizes. The $50 \mathrm{~nm}$ GNPs were taken up by liver macrophages faster and to a greater extent than smaller GNPs; the particles were eliminated after uptake. This result is correlated with the inflammatory response of the liver.

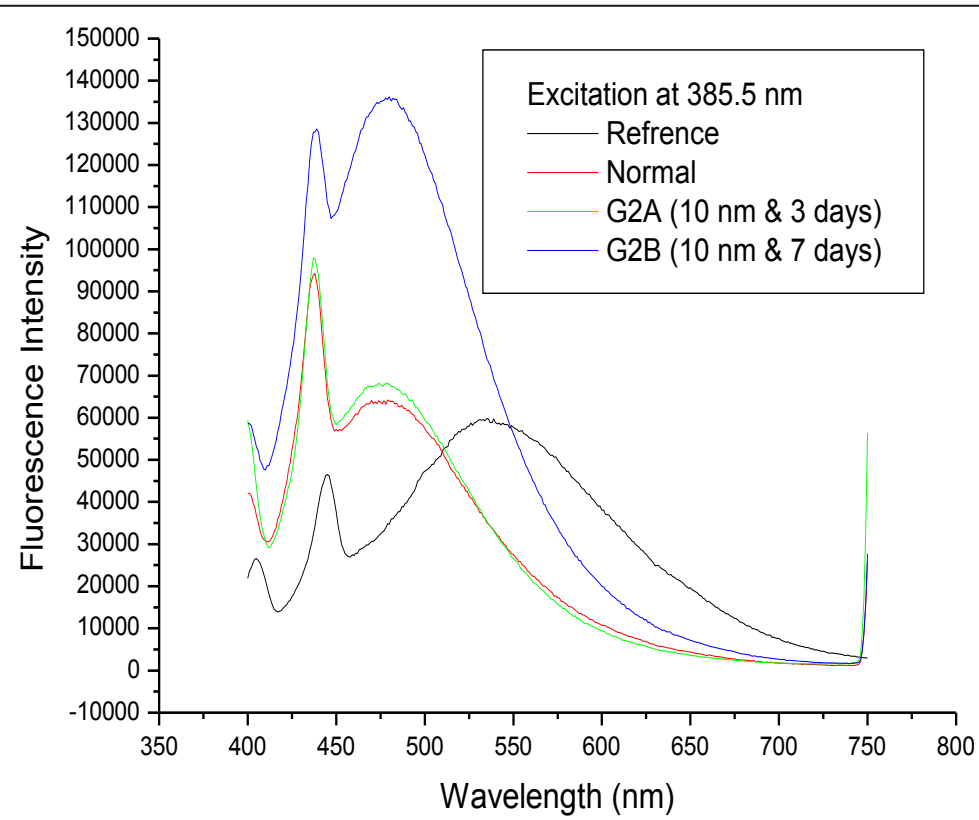

Figure 3 The fluorescence emission peak intensity after infusion periods of 3 and 7 days for $10 \mathrm{~nm}$ GNPs. 


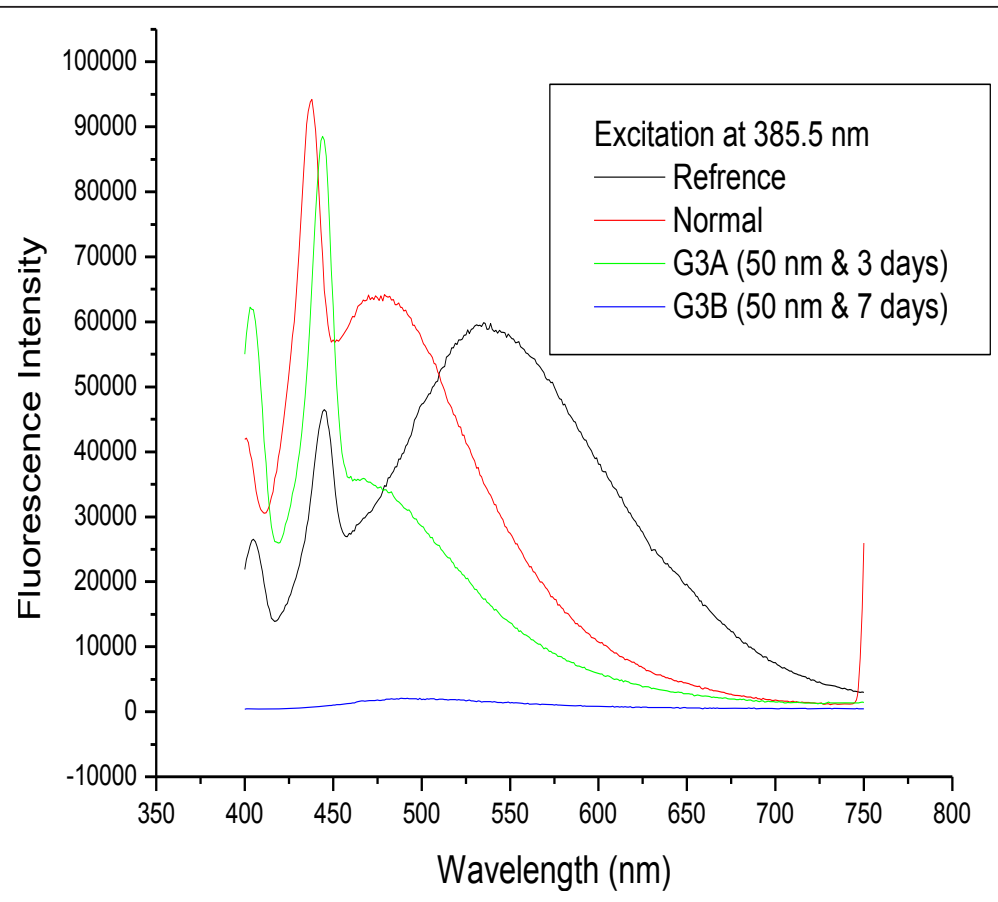

Figure 4 The fluorescence emission peak intensity after infusion periods of 3 and 7 days for $50 \mathrm{~nm}$ GNPs

The present results show that $50 \mathrm{~nm}$ GNPs may be cleared via urine and bile rapidly. Nanoparticles for therapeutic use need to have a long retention time in order to encounter and interact with the desired target. However, a long retention time can result in toxic effects in vivo.
Thus, route and rate of nanomaterial clearance is an important issue [28,29].

Absorbed nanoparticles in the systemic circulation can be excreted through various routes, such as the kidneys or bile. Renal clearance of solid nano-sized materials is

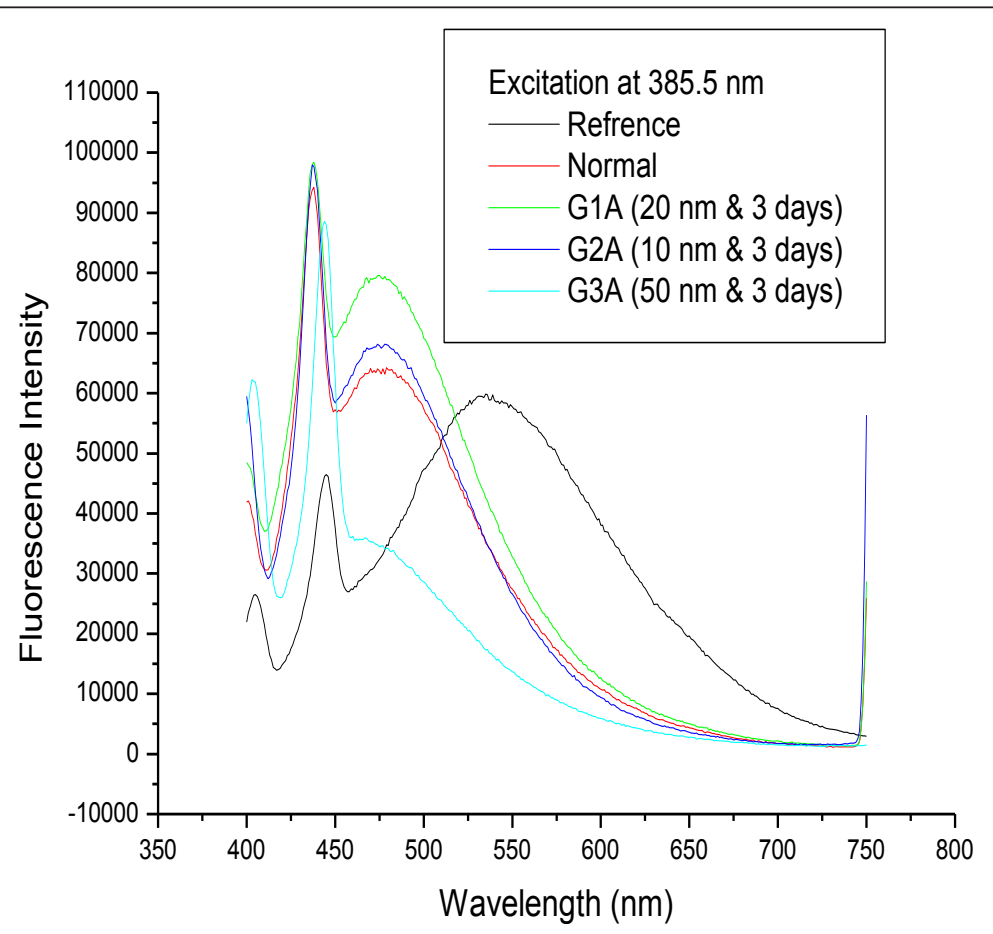

Figure 5 The fluorescence emission peak intensity after infusion period of 3 days for 10, 20 and $50 \mathrm{~nm}$ GNPs. 


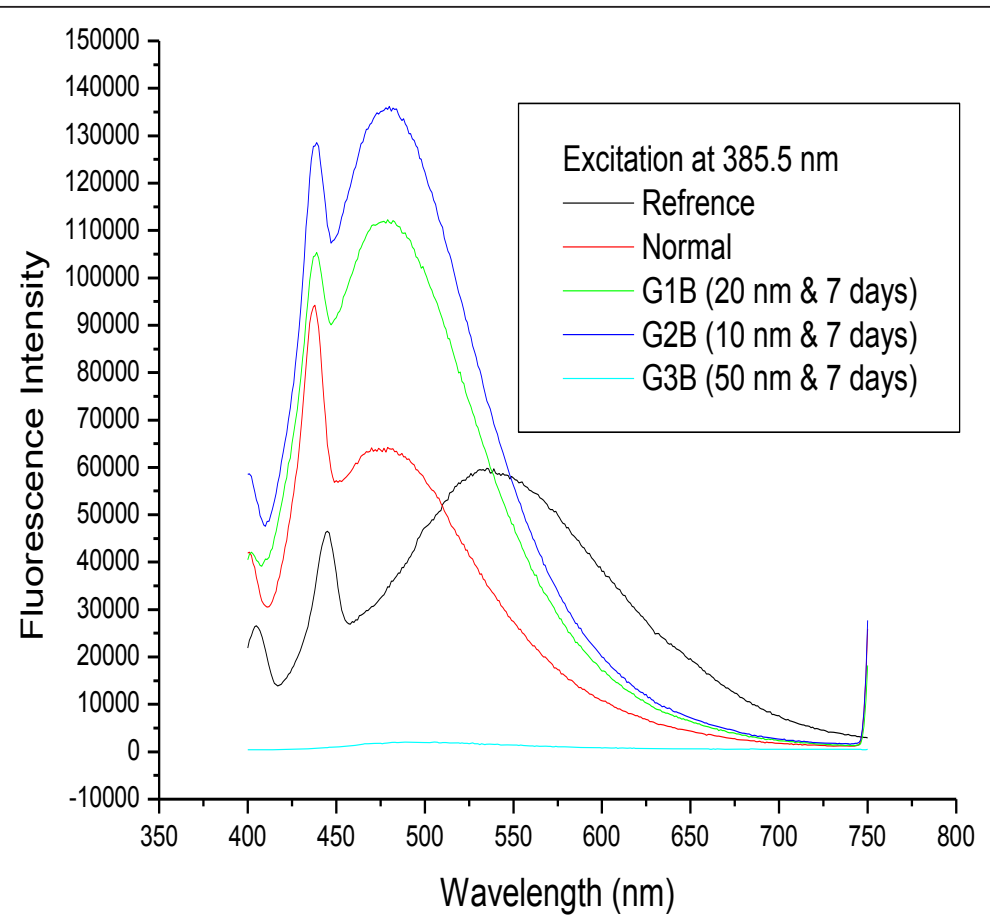

Figure 6 The fluorescence emission peak intensity after infusion period of 7 days for 10, 20 and $50 \mathrm{~nm}$ GNPs.

known to be influenced by particle size and surface charge $[29,30]$. In the present study, we monitored the fluorescence intensity and tissue distribution of three different GNP preparations of varying particle size after intravenous injection into rats over periods of 3 or 7 days. We found that GNP fluorescence intensity and liver tissue distribution varied with particle size. The fluorescence intensity for 10 and $20 \mathrm{~nm}$ GNPs increased as the infusion period increased from 3 to 7 days, while it decreased during this period for $50 \mathrm{~nm}$ GNPs. Larger-sized particles gave lower

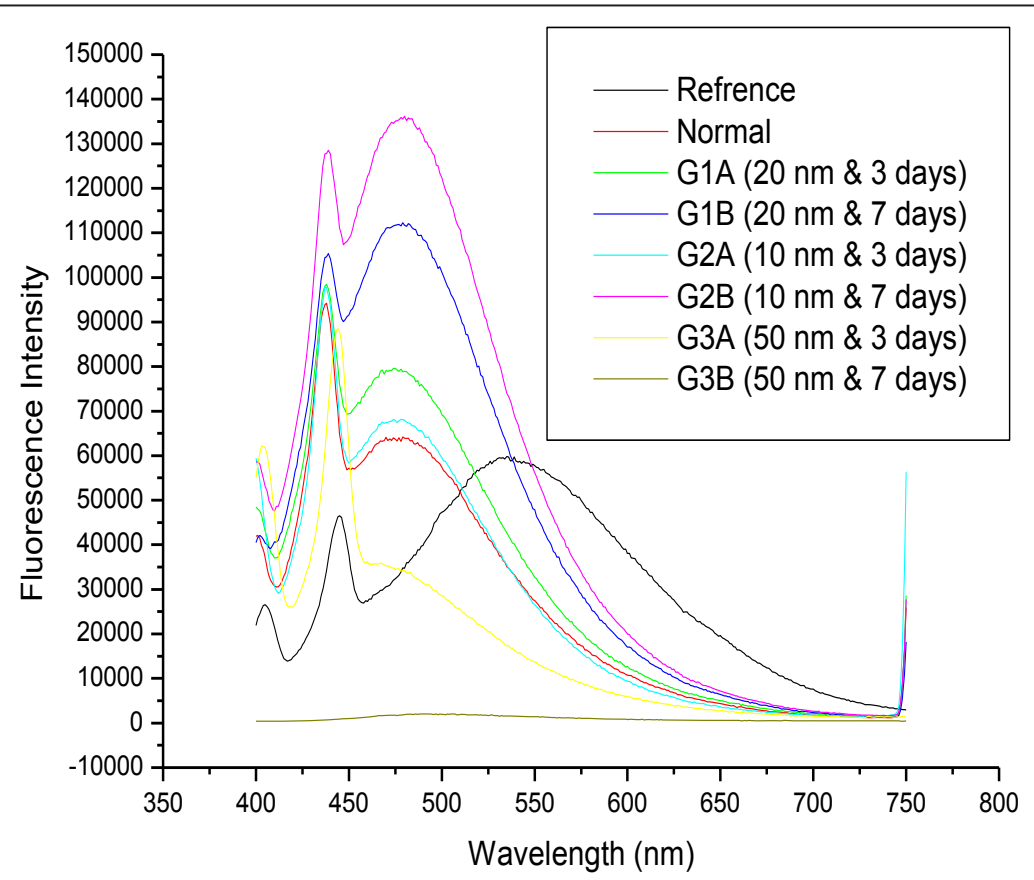

Figure 7 The fluorescence emission peak intensity after infusion periods of 3 and 7 days for 10, 20 and $50 \mathrm{~nm}$ GNPs 
fluorescence intensity because more particles were trapped by macrophages.

All GNPs showed a propensity to accumulate in tissues following injection. The liver tissue distribution of GNPs was size dependent: the smallest particles showed the most widespread organ distribution. Smaller GNPs also showed greater accumulation in cells according to dose-metric treatment. Therefore, it should be taken into consideration that GNPs preferentially target organs with many phagocytic cells, such as kidney, spleen, lung, heart and mesenteric lymph nodes.

\section{Conclusions}

High electron density and homogeneous shape and size make GNPs highly conspicuous in TEM images. We found that the 10 and $20 \mathrm{~nm}$ GNP preparations exhibit spherical morphology, while $50 \mathrm{~nm}$ GNPs are hexagonal.

The size (i.e., surface area to volume ratio), shape and concentration of GNPs all contributed to differences in the fluorescence intensities between GNP samples. The time dependence of GNP fluorescence spectra was also dependent on these factors; smaller particles generally exhibited higher fluorescence that increased with GNP infusion time, whereas larger GNPs exhibited lower fluorescence decreasing with infusion time.

This study suggests that fluorescence intensity may be a useful diagnostic probe for bioaccumulation and toxicity of gold nanoparticles administered to rats. Moreover, smaller particles, which have an increased ratio of surface area to volume, appear to be more reactive toward one another (resulting in aggregation) and toward biological components in the surrounding environment.

\section{Acknowledgements \\ The authors are very grateful to the National Plan of Science and Technology (NPST). This research was financially supported by the National Science and Technology Innovation Plan (NSTIP), Research No. 08-ADV206- 02 and Research No. 09-NAN670-02, College of Science, King Saud University, Saudi Arabia. \\ Author details \\ 'Department of Physics and Astronomy, College of Science, King Saud University, P.O. 2455, Riyadth 11451, Saudi Arabia. ${ }^{2}$ Biophysics Department, Faculty of Science, Cairo University, 12613 Giza, Egypt.}

\section{Authors' contributions}

MAKA and MMM have analyzed the data, interpreted and written the final draft of this manuscript. The animal model used in this study was obtained from the Laboratory Animal Center (College of Pharmacy, King Saud University, Saudi Arabia). MAKA has conceived the study and its design and obtained research grants for this study. Moreover, both authors have read and approved the final manuscript.

\section{Competing interests}

The authors declare that they have no competing interests.

Received: 27 September 2011 Accepted: 31 October 2011 Published: 31 October 2011
References

1. Caruthers SD, Wickline SA, Lanza GM: Nanotechnological applications in medicine. Curr Opin Biotechno 2007, 18:26-30.

2. Braydich-Stolle L, Hussain S, Schlager JJ, Hofmann M: In Vitro Cytotoxicity of Nanoparticles in Mammalian Germline Stem Cells. Toxicol Sci 2005, 88:412-419.

3. Oberdörster G, Maynard A, Donaldson K, Castranova V, Fitzpatrick J, Ausman K, Carter J, Kan B, Kreyling W, Lai D, Olin S, Monteiro-Riviere N, Warheit D: Principles for characterizing the potential human health effects from exposure to nanomaterials: elements of a screening strategy. Particle and Fibre Toxicology 2005, 2:13-35.

4. Foster W, Ruka M, Gareau P, et al: Morphologic characteristics of endometriosis in the mouse model: application to toxicology. Can J Phsiol Pharmacol 1997, 75:1188-1196.

5. Pissuwan D, Valenzuela SM, Cortie MB: Therapeutic possibilities of plasmonically heated gold nanoparticles. Trends Biotechno 2006, 24:62-67.

6. Kogan MJ, Olmedo I, Hosta L, Guerrero AR, Cruz LJ, Albericio F: Peptides and metallic nanoparticles for biomedical applications. Nanomedicine 2007, 2:287-306.

7. El-Sayed $I H$, Huang $X$, El-Sayed MA: Selective laser photo-thermal therapy of epithelial carcinoma using anti-EGFR antibody conjugated gold nanoparticles. Cancer Lett 2006, 239:129-135.

8. Kogan MJ, Bastus NG, Amigo R, Grillo-Bosch D, Araya E, Turiel A, Labarta A, Giralt $E$, Puntes VF: Nanoparticle-mediated local and remote manipulation of protein aggregation. Nano Lett 2006, 6:110-115.

9. Zharov VP, Mercer KE, Galitovskaya EN, Smeltzer MS: Photothermal nanotherapeutics and nanodiagnostics for selective killing of bacteria targeted with gold nanoparticles. Biophys J 2006, 90:619-627.

10. Semmler-Behnke M, Kreyling WG, Lipka J, Fertsch S, Wenk A, Takenaka S, Schmid G, Brandau W: Biodistribution of 1.4- and 18-nm gold particles in rats. Small 2008, 4:2108-2111.

11. Schmid G: Large clusters and colloids. Metals in the embryonic state. Chem Rev 1992, 92:1709.

12. Jain P, El-Sayed I, El-Sayed M: Au nanoparticles target cancer. Nano Today 2007, 2:18-29.

13. Tian ZQ, Bin R, Wu DY: Surface-Enhanced Raman Scattering: From Noble to Transition Metals and from Rough Surfaces to Ordered Nanostructures. J Phys Chem B 2002, 106:9463-9483.

14. Kamat PV: Photophysical, Photochemical and Photocatalytic Aspects of Metal Nanoparticles. J Phys Chem B 2002, 106:7729-7744.

15. Shipway AN, Eugenii K, Itamar W: Nanoparticle Arrays on Surfaces for Electronic, Optical, and Sensor Applications. Chem Phys Chem 2000, 1:18-52.

16. Kuwahara Y, Yamada S: Facile Fabrication of Photoelectrochemical Assemblies Consisting of Gold Nanoparticles and a Tris(2, 2'-bipyridine) ruthenium(II)-Viologen Linked Thiol. Langmuir 2001, 17:5714-5716.

17. Mirkin CA, Letsinger RL, Mucic RC, Storhoff JJ: A DNA-based method for rationally assembling nanoparticles into macroscopic materials. Nature 1996, 382:607-609.

18. Huber M, Wei TF, Muller UR, Lefebvre PA, Marla SS, Bao YP: Gold nanoparticle probe-based gene expression analysis with unamplified total human RNA. Nucleic Acids Res 2004, 32:e137-e145.

19. Wang X, Duan S, Geng B, Cui J, Yang Y: Schmeissneria: A missing link to angiosperms? BMC Evol Biology 2007, 7:1-13

20. Nel A, Xia T, Mädler L, Li N: Toxic Potential of Materials at the Nanolevel. Science 2006, 311:622-627.

21. Liu WT: Nanoparticles and their biological and environmental applications. J Biosci Bioeng 2006, 102:1-7.

22. Baptista P, Pereira E, Eaton P, Doria G, Miranda A, Gomes I, et al: Gold nanoparticles for the development of clinical diagnosis methods. Anal Bioanal Chem 2008, 391:943-50.

23. Hillyer JF, Albrecht RM: Gastrointestinal persorption and tissue distribution of differently sized colloidal gold nanoparticles. J Pharm Sci 2001, 90:1927-1936.

24. Sonavane G, Tomoda K, Makino K: Biodistribution of colloidal gold nanoparticles after intravenous administration: effect of particle size. Colloids Surf B Biointerfaces 2008, 66:274-280.

25. De Jong WH, Hagens WI, Krystek P, Burger MC, Sips AJ, Geertsma RE: Particle size-dependent organ distribution of gold nanoparticles after intravenous administration. Biomaterials 2008, 29:1912-1919. 
26. Hainfeld JF, Slatkin DN, Focella TM, Smilowitz HM: Gold nanoparticles: a new X-ray contrast agent. Brit J Radiol 2006, 79:248-253.

27. Shrestha S, Yeung C, Nunnerley C, Tsang S: Comparison of morphology and electrical conductivity of various thin films containing nanocrystalline praseodymium oxide particles. Sens Actuators A Phys 2006, 136:191-8.

28. Cho W-S, Cho M, Jeong J, Choi M, Han BS, Shin H-S, Hong J, Chung BH, Jeong J, Cho M-H: Size-dependent tissue kinetics of PEG-coated gold nanoparticles. Toxicology and Applied Pharmacology 2010, 245:116-123.

29. Choi CJ, Anantharam V, Nathan J, Saetveit NJ, Houk RS, Arthi Kanthasamy A, Anumantha G, Kanthasamy AG: Normal Cellular Prion Protein Protects against Manganese-induced Oxidative Stress and Apoptotic Cell Death. Toxicol Sci 2007, 52:280-283.

30. Gupta R: System behaviour of wood truss assemblies. Progress in Structural Engineering and Materials 2005, 7:183-193.

\section{doi:10.1186/1476-511X-10-195}

Cite this article as: Abdelhalim and Mady: Liver uptake of gold nanoparticles after intraperitoneal administration in vivo: A fluorescence study. Lipids in Health and Disease 2011 10:195.

\section{Submit your next manuscript to BioMed Central} and take full advantage of:

- Convenient online submission

- Thorough peer review

- No space constraints or color figure charges

- Immediate publication on acceptance

- Inclusion in PubMed, CAS, Scopus and Google Scholar

- Research which is freely available for redistribution

Submit your manuscript at www.biomedcentral.com/submit 